www.jmscr.igmpublication.org Impact Factor 5.244

Index Copernicus Value: 83.27

ISSN (e)-2347-176x ISSN (p) 2455-0450

crossref DOI: _https://dx.doi.org/10.18535/jmscr/v4i12.23

\title{
Diagnosis of Pneumonia in Children with Severe Acute Malnutrition, Validation of WHO Recommended Criteria and Pulse-Oximetry
}

\author{
Authors \\ Mohd Raza', Farzana K. Beig ${ }^{2}$ \\ Senior Resident, Dept of Pediatrics, J.N. Medical College, A. M. U. Aligarh, Uttar Pradesh, India \\ Email: razamobin786@gmail.com \\ Professor, Dept of Pediatrics, J.N. Medical College, A. M. U. Aligarh, Uttar Pradesh, India \\ Email:fkbeig@hotmail.com \\ Corresponding Author \\ Mohd Raza
}

Address c/o 1191/00C2 Chaman Palace Al-Hamd Apartment near Nadeem Tarin Hall, Sir Syed Nagar, Aligarh, Uttar Pradesh, India, 202001

\begin{abstract}
Aim: To find incidence of clinical pneumonia viz a viz radiologically confirmed pneumonia in children with severe acute malnutrition.

Materials and Methods: It was a hospital based prospective analytical study carried out over a period of 12 months from January 2013 to December 2013. 184children with SAM admitted to paediatrics ward were evaluated for pneumonia as per WHO criteria. Besides the routine investigations, each patient was subjected to $X$-ray chest, pulse-oximetry and Montoux test and the results were correlated.

Results: Out of 184 patients with SAM, 52 (28.26\%) had features of clinical pneumonia but 7 (3.8\%) out of them had a normal X-ray chest. Similarly, 15 (8.15\%) cases had definite radiological features of pneumonia however, they did not fit into the clinical diagnostic criteria. Moreover, 6 of these 15 cases (40\%) had hypoxia (Spo2< $90 \%$ at room air) on pulse-oximetry at the time of admission.

Conclusion: WHO recommended clinical criteria; if used alone is inadequate for diagnosis of pneumonia in children with SAM as occult pneumonia was seen in about $25 \%$ cases. Traditionally used X-ray chest should be made a basic cornerstone for diagnosis of pneumonia. Moreover, on pulse-oximetry, 40\% of occult pneumonia cases showed hypoxia; thereby making it a useful adjunct in diagnosing pneumonia cases.

Keywords: Pneumonia, SAM, Occult pneumonia, Pulse-oximetry, Chest X-ray.
\end{abstract}

\section{INTRODUCTION}

Pneumonia is currently the leading cause of childhood death in developing countries, including India ${ }^{(1)}$, constituting $19 \%$ of the total 10.6 million deaths among children aged less than five years, that occur globally each year, and nearly all of these deaths occur in developing countries ${ }^{(2)}$. Malnutrition is a common co-morbidity in such communities ${ }^{(3)}$ and is a major risk factor for deaths due to pneumonia ${ }^{(4)}$; the risk increases with increasing severity of malnutrition (5) and also when treatment is delayed ${ }^{(6)}$. Early and efficient management can reduce case-fatality rates from pneumonia ${ }^{(7)}$. In resource-poor settings, health professionals often rely heavily on clinical assessment alone in diagnosing 
pneumonia; however, clinical signs may be protean in severely-malnourished children ${ }^{(5,8)}$. WHO recommended clinical signs are often not found in malnourished children, hence the diagnosis is likely to be missed ${ }^{(9,10)}$. Occult pneumonia is defined as "Radiographic pneumonia in a patient without signs of pneumonia" it may occur in severely-malnourished children.

Although X-ray chest does not give a reliable answer to aetiology, but it does diagnose pneumonia with certainty and hence can be taken as gold standard ${ }^{(11,12,13)}$. There are very few studies conducted in last 10 years on clinical and laboratory features of pneumonia in malnourished children ${ }^{(14)}$.

This prospective observational analytical study was thus under taken to find the incidence of clinical, radiological and occult pneumonia in children admitted with severe acute malnutrition and to evaluate various parameters used to diagnose these cases with respect to their predictive capability.

\section{MATERIALS AND METHODS}

\section{Inclusion criteria-}

All malnourished children age between 2-59 months admitted to paediatrics ward of JNMCH, AMU over a period of 12 months from January 2013 to December 2013.

\section{Exclusion criteria-}

Known or clinically recognizable causes of difficulty in breathing were excluded like

- Bronchial asthma that responds to trial of nebulisation.

- Suspected surgical pathology.

- Foreign body inhalation

- Poisoning

- Dehydration

- Acidosis

A detailed history and examination was done and the subjects were categorised as having clinical pneumonia based on the established WHO criteria (16)
Anthropometric analysis of the subjects including the following measurements was done and patients were classified into SAM as per WHO criteria $^{(15)}$.

- Weight: It was measured using a digital weighing scale having an accuracy of 0.05 kilograms in children.

- Height/length: It was measured by infantometer in children less than 2 years and by a portable stadiometer, with the subject standing bare footed against a standard vertical sliding scale in children greater than 2 years.

- MUAC: It was measured by using measuring tape with least count of $0.1 \mathrm{~cm}$; at a point midway between acromian process and olecranon process. MUAC of less than $11.5 \mathrm{~cm}$ will be considered malnourished.

- Haemogram, Montoux test and Pulse Oximetry was done in all children right at the time of examination. A baseline blood culture and chest roentgenogram were also done in each patients at the time of admission. Postero- anterior view were taken and all the skiagrams were read independently by both the radiologist and paediatrician to minimise inter-observer error.

- Those with following radiological findings were classified as having pneumonia ${ }^{(12,13)}$.

$>$ Dense opacity,

$>$ Fluffy chest infiltrates

$>$ Consolidation of a portion or whole of a lobe or of the entire lung.

All the patients were started empirically on antibiotics (Ampicillin and Gentamycin) and the medication were further changed if the patients deteriorated after 48 hours or didn't improve after 72 hours ${ }^{(17)}$. This study was approved by the institutional Ethical Committee and an informed/ implied consent was taken from all the study subjects as per required. 


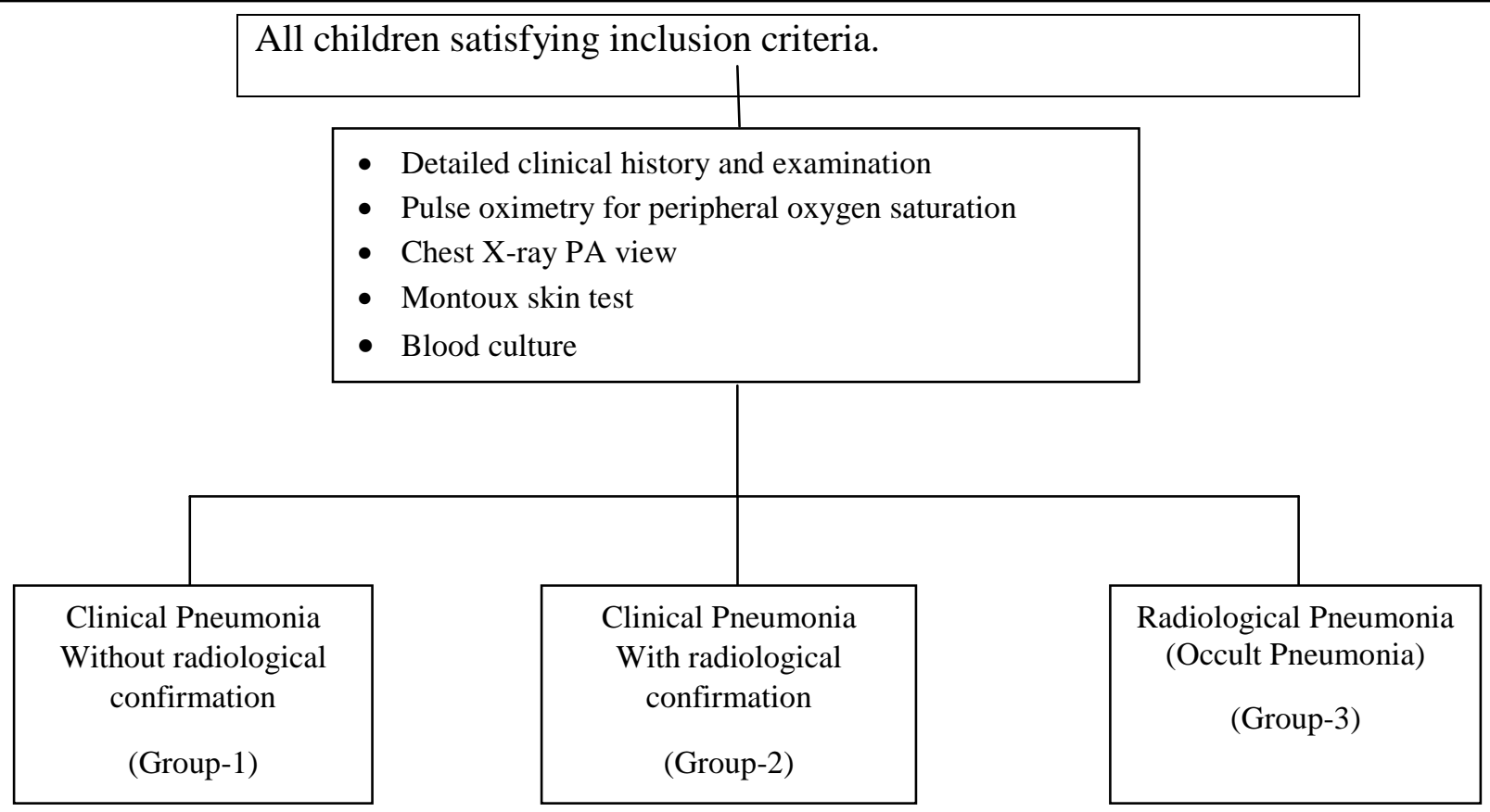

\section{RESULTS}

The mean age of 184 children was 12.02 months. They were 116 boys (63\%) and 68 girls (37\%). Baseline characteristics of the patients and the controls were shown in Table 1.

Out of 184 patients, there were 67 (36.4\%) cases of pneumonia. The number of patients having Clinical pneumonia with and without radiological confirmation were $45(67 \%)$ and $7(10.4 \%)$ respectively (Table 2). However, 15 children $(12.8 \%)$ who did not have any respiratory symptoms on presentation were also found to have radiological features of pneumonia (Occult pneumonia). 6 (40\%) of these 15 showed an added feature of hypoxia (Spo2< $90 \%$ at room air) on pulse oximetry.

Table 1. Baseline characteristics of patients

\begin{tabular}{|cl|l|}
\hline Item & $\begin{array}{l}\text { Malnourished children } \\
\text { (Data are presented mean } \pm \mathrm{SD})\end{array}$ \\
\hline - Age (months) & $12.02 \pm 9.04$ \\
- Sex $(\mathrm{M} / \mathrm{F})$ & $116 / 63$ \\
- Weight $(\mathrm{kg})$ & $5.38 \pm 1.86$ \\
- Height $(\mathrm{cm})$ & $65.79 \pm 8.58$ \\
- MUAC $(\mathrm{cm})$ & $10.33 \pm 1.36$ \\
- Haemoglobin $(\mathrm{g} / \mathrm{dl})$ & $10.14 \pm 1.91$ \\
\hline
\end{tabular}

Table 2 (Number of patients in three different groups)

\begin{tabular}{|l|c|c|c|}
\hline $\begin{array}{l}\text { Clinical Pneumonia } \\
\text { Without radiological } \\
\text { (Group-1) }\end{array}$ & $\begin{array}{c}\text { Clinical Pneumonia } \\
\text { With radiological } \\
\text { confirmation } \\
\text { (Group-2) }\end{array}$ & $\begin{array}{c}\text { Radiological } \\
\text { pneumonia (Occult } \\
\text { pneumonia) } \\
\text { (Group-3) }\end{array}$ & $\begin{array}{c}\text { TOTAL } \\
\text { PNEUMONIA } \\
\text { CASES }\end{array}$ \\
\hline 7 & 45 & 15 & 67 \\
\hline
\end{tabular}


Table 3: Clinical versus Radiologically defined Pneumonia (contingency table)

\begin{tabular}{|c|c|c|c|c|c|}
\hline & \multicolumn{2}{|c|}{ Radiological pneumonia } & \multirow[b]{2}{*}{ Total } & \\
\hline & & Yes & No & & \\
\hline \multirow{2}{*}{$\begin{array}{l}\text { Signs } \\
\text { symptoms } \\
\text { of } \\
\text { Pneumonia }\end{array}$} & Yes & $\begin{array}{c}45 \\
(86.5 \%)\end{array}$ & $\begin{array}{c}7 \\
(13.4 \%)\end{array}$ & 52 & \multirow{3}{*}{$\begin{array}{l}\text { Sensitivity-75\% } \\
\text { Specificity-94.3\% } \\
\text { PPV-86.5\% } \\
\text { NPV-88.6\% }\end{array}$} \\
\hline & No & $\begin{array}{c}15 \\
(11.3 \%) \\
\end{array}$ & $\begin{array}{c}117 \\
(88.6 \%) \\
\end{array}$ & 132 & \\
\hline \multicolumn{2}{|l|}{ Total } & $\begin{array}{c}60 \\
(32.6 \%) \\
\end{array}$ & $\begin{array}{c}124 \\
(67.3 \%) \\
\end{array}$ & 184 & \\
\hline
\end{tabular}

\section{DISCUSSION}

As per the WHO defined clinical criteria, 52 $(28.26 \%)$ cases of pneumonia were picked up but 15 cases of occult pneumonia have been missed. Thus, clinical criteria used alone had positive predictive value of $86.53 \%$ and negative predictive value of $88.6 \%$. Similar incidence of occult pneumonia was found in previous studies $(18,19)$

Out of 7 cases of clinical pneumonia without radiological confirmation, 3 presented with Bronchiolitis, 2 with severe anaemia with acidosis and 2 patients had high grade fever. Thus, as a predictor of pneumonia, X-ray chest had a sensitivity of $75 \%$ and specificity of $94.35 \%$.

3 out of $15(8.15 \%)$ cases of occult pneumonia were diagnosed as tubercular pneumonia on the basis of history of contact and Montoux test and chest x-ray showed non-resolving pneumonia.

Out of 15 confirmed cases of occult pneumonia 12 $(80 \%)$ children showed hypoxia (spo2 $<95 \%$ at room air) and6 (40\%) of them showed Spo $2<90 \%$ at room air thereby; making pulse-oximetry as a significant predictor of pneumonia in our setting. Also, as pulse-oximetry is more objective and cheaper than radiography, its role as a clinical and investigative tool merits further exploration.

These results suggest that WHO recommended clinical signs for the diagnosis of pneumonia in severely malnourished children are not sensitive enough when used solely as predictors of pneumonia. Clinical signs of pneumonia may be absent in severely-malnourished children due to sub-optimal inflammatory responses, reduced power of the respiratory muscles, and depletion of potassium and magnesium. Severe malnutrition also contributes to immune deficiency and reduced host-defence. Reduced clinical signs of pneumonia in severely malnourished children have previously been reported; however, we could not find any report of radiological pneumonia in absence of all the clinical signs in such populations.

We thus conclude that occult pneumonia in severely malnourished infants and young children is a reality and not a myth. Therefore, a vigilant work up of such cases including a constellation of clinical assessment, radiological findings as well as use of pulse-oximetry is must by the physicians to search for any possibility of occult pneumonia in order to start early and appropriate management thereby, reducing morbidity and mortality.

\section{ACKNOWLEDGMENTS}

We would like to express our sincere thanks to my study guide and co-residents, nurses, members of MTU for invaluable support and contribution during patient enrolment and data collection. We would also like to express our gratitude to caregivers/ mothers of the study participants for their consent to enroll their children in the study.

\section{REFERENCES}

1. Naheed A, Saha SK, Breiman RF, Khatun F, Brooks WA, El Arifeen $\mathrm{S}$ et al. Multihospital surveillance of pneumonia burden among children aged $<5$ years hospitalized for pneumonia in Bangladesh. Clin Infect Dis 2009;48 (Suppl 2):S82-9. 
2. Bryce J, Boschi-Pinto C, Shibuya K, Black RE. WHO estimates of the causes of death in children Lancet 2005;365:1147-52.

3. Chisti MJ, Hossain MI, Malek MA, Faruque AS, Ahmed T, Salam MA. Characteristics of severely malnourished under-five children hospitalized with diarrhoea, and their policy implications. Acta Paediatr 2007;96:693-6.

4. Chisti MJ, Huq S, Das SK, Malek MA, Ahmed T, Faruque AS et al. Predictors of severe illness in children under age five with concomitant infection with pneumonia and diarrhoea at a large hospital in Dhaka, Bangladesh. Southeast Asian J Trop Med Public Health 2008;39:719-27.

5. Chisti MJ, Tebruegge M, La Vincente S, Graham SM, Duke T. Pneumonia in severely malnourished children in developing countries - mortality risk, aetiology and validity of WHO clinical signs: a systematic review. Trop Med Int Health 2009;14:1173-89.

6. Suskind D, Murthy KK, Suskind RM. The malnourished child: an overview. In: Suskind RM, Lewinter-Suskind L, editors. The malnourished child. New York, NY: Vevey/Raven Press, 1990:1-22.

7. Graham SM, English M, Hazir T, Enarson $\mathrm{P}$, Duke Challenges to improving case management of childhood pneumonia at health facilities in resource-limited Settings. Bull World Health Organ 2008; 86:349-55.

8. Falade AG, Tschappeler H, Greenwood BM, Mulholland EK. Use of simple clinical signs to predict pneumonia in young Gambian children: the influence of malnutrition. Bull World Health Organ 1995;73:299-304.

9. Bachur R, Perry H \& Harper MB. Occult pneumonias: empiric chest radiographs in febrile children with leucocytosis. Annals of Emergency Medicine 1999;33:166-173.
10. Murphy CG, Van De Pol AC, Harper MB \& Bachur RG. Clinical predictors of occult pneumonia in the febrile child Academic Emergency Medicine 2007;14: 243-249.

11. Sarria E, Fischer GB, Lima JA, Menna Barreto SS, Flores JA \& Sukiennik R. Interobserver agreement in the radiological diagnosis of lower respiratory tract infections in children. Journal of Pediatrics (Rio J) 2003;79:497-503.

12. Bada C,Carreazo NY, Chalco JP \& Huicho $\mathrm{L}$ Inter-observer agreement in interpreting chest X-rays on children with acute lower respiratory tract infections and concurrent wheezing. Sao Paulo Medical Journal 2007;125:150-154

13. Pauls S, Kruger S, Richter K et al. Inter observer agreement in the assessment of pulmonary infiltrates on chest radiography in community-acquired pneumonia. RöfoFortschritte auf dem Gebieta der Röntgenstrahlen and der Nuklearm-ediin 2007;179:1152-1158.

14. Chisti MJ, Ahmed T, Faruque AS, Abdus Salam M Clinical and laboratory features of radiologic pneumonia in severely malnourished infants attending an urban diarrhoea treatment centre in Bangladesh. The Pediatric infectious disease journal 2010;29:174-7

15. WHO Child Growth Standards and the Identification of Severe Acute Malnutrition in Infants and Children. A joint statement by WHO and UNICEF, 2009. Accessed from http://www.who.int/nutrition/publications/ severe malnutrition/9789241598163_eng.pdf

16. Pneumonia: The forgotten killer of children. The United Nations Children's Fund (UNICEF)/World Health Organization (WHO), 2006

17. Stephen M Graham Challenges to improving case management of childhood pneumonia at health facilities in resource- 
limited settings. Bulletin of the World Health Organization 2008;86:349-355.

18. Rutman MS, Bachur R, Harper MB Radiographic pneumonia in young, highly febrile children with leucocytosis before and after universal conjugate pneumococcal vaccination. PediatrEmerg Care. 2009 Jan;25(1):1-7.

19. Murphy CG, van de Pol AC, Harper MB, Bachur RG AcadEmerg Med Clinical predictors of occult pneumonia in the febrile child. 2007 Mar;14(3):243-9. 